\title{
Research on the Application of Reductive Active Learning Method in the Design of Transmission Teaching Aids
}

\author{
Zeyu $\mathrm{Xu}^{1}$, Chundong $\mathrm{Ma}^{1,2}$, Yong $\mathrm{Zhang}^{1 *}$, Hongjie $\mathrm{Yu}^{1}$ and Honghe $\mathrm{Gao}^{1}$ \\ ${ }^{1}$ School of Art and Design, Liaoning Shihua University, Fushun, Liaoning Province, 113001, China \\ ${ }^{2}$ School of Design, Dalian Minzu University, Dalian, Liaoning Province, 116600, China
}

\begin{abstract}
In view of the dual pressure of examination oriented and extra-curricular counseling in primary education, this paper discusses the relationship between knowledge acquisition and perceptual experience through the design of teaching aids according to the educational concept of reductive active learning method. Based on life style as logic, the interesting transmission mode is established, and the mechanical knowledge related to force and transmission is transformed into teaching aids that conform to the cognitive law of children aged 6-12. Children get sensory experience through practical operation. Therefore, it enriches the content of science course in primary school, and establishes the perceptual experience foundation for the later learning of mathematics, machinery and physics.
\end{abstract}

\section{Introduction}

Relevant data from the 2018 China online education industry development report show that education expenditure accounts for $25 \%$ of household consumption. A child will spend about 1 million yuan from birth to work, and up to 3 million in some wealthy families. This shows that these families pay much attention to attention. Education has also developed in accordance with the needs of society and social change. Today, education concepts and teaching methods have ushered in a period of diversity. Return to the essence of education and effective teaching concepts[1], people can be easily attracted by the learning method which puts the students in the center. Therefore, modern education should pay more attention to the development of children's learning ability and creativity[2]. The perspective of biology point out that knowledge grows out, and the structure of knowledge can grow like stem cells, like an open system which can also be extended. Learning knowledge is a process of stimulating the growth of neurons. The learning process should not use the traditional method of rote learning. For children, toys are teaching aids, and teaching aids are also toys. Children operate absorbedly and happily, in the mean time they can learn knowledge happily. Children 's education from preschoolers has used a social and collective way to establish a cognitive learning system, marking the stage where family education and social public education are combined. Based on the cognitive law of children aged 6 to 12 , combined with reductive active learning method, they explore the senses in depth The connection between experience and the design of transmission teaching aids guides children to directly study things, obtain feelings[3], generate questions and understandably receive knowledge, and explore knowledge. Teaching aid design as a medium for knowledge transfer also has new design ideas in children's education and design thinking and inquiry, building interest and gaining self-confidence are the keys to education. Modern education promotes stem, and the implantation of science curriculum content in the elementary school stage can make children get a perceptual experience in activity operations, building the perceptual foundation for later Learning of mathematical, mechanical and physical knowledge[4].

\section{Reductive active learning}

Let children study things directly, get feelings from them, generate doubts, and then put the predecessors' theory back into things to understand, realistically test, and creatively propose ideas (solve the problem), which is reductive active learning method. On December 7th 2019, JIJIMI ART \& SCIENCE MUSEUM (JJM) was settled in Dalian, China. JJM is another educational brand focusing on basic science education for children in China. JJM is the first art science experience play center in the form of a museum in China, is also an educational practice base and experience center for the reductive active learning method. This learning method participate purposefully in the process of experiencing some things, generate first-hand experience, and develop skills and gain knowledge through first-hand experience. Children's learning process is not accept ready-made knowledge passively and simply, but by looking more, listening more, and doing more, so that they can actively acquire knowledge and methods, that is to say, exploring and learning through playing.

Learning by doing is a specific method of education, which guides children to combine "playing" with 
"learning". It can not only stimulate their desire for knowledge in a happy "playing" experience and harvesting experience, but also improve their operational ability[5]. What' s more, it can stimulate their creative potential when they are playing. For children, play is his life and a way of exploring the world.

Children receive information through the five senses while playing, and they will have emotional responses like anger, sorrow and joy. This response stimulates the development of neurons. Axons and dendrites will be active as long as they are stimulated by information. When they grow to a certain stage, they will naturally establish the information association, which is the so-called selflearning. At this time, children can stimulate the brain to grow the corresponding neural structure when experiencing things, thereby forming memory and experience.

Therefore, for children the reductive active learning method hopes that children can experience things, transform emotions into specific stimulus responses, and gain a more self-experience, so as to obtain implicit memory.

\section{Children's cognitive law and the basis of teaching aid design}

\subsection{Children's cognitive characteristics}

At first, humans' perception of the world was felt through five senses. Children's awareness and perception of the objective world through audiovisual smells, and the information transmitted by their brains begins to establish pathways for specific things. The process of children's cognition is the process of obtaining self-validation through contacting with things. Therefore, they need to rely on the five senses to directly perceive object properties and experiences, like hard or soft, hot or cold, etc. to gain experience. Children's cognitive processes and characteristics, as shown in Figure 1.

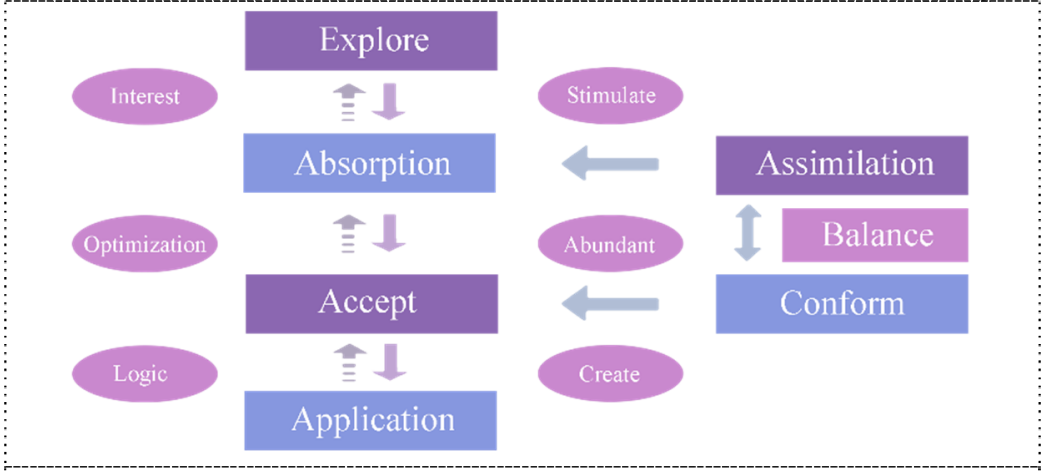

Figure 1. Children's cognitive processes and characteristics.
If you want to understand the real world more deeply, you need to contact with things by yourself. Like many children, they will grab objects and nibble, just because of their uncertainty about this thing. They will establish empirical evidence through touching, which is exploration. Children can form different emotional experiences through the contact of the five senses[6], which are then converted into implicit memory. For children, the more mature the skin perception is, the more perfect the brain's ability to process information, and the more it will accept information. You can also put the application of the knowledge system into use at a later stage. Children are young and have less experience value, and the ability to process information is not relatively complete at the beginning, so many cognitive barriers will be generated. Understanding children's recognition rules and avoiding Cognitive barriers have a positive effect on teaching aid design.

3.1.1. Perceptual barrier. Childhood cognition is still developing, and most of the sensitivity to things is driven by interest, and for things that are not of interest, the input of information is automatically shielded. Therefore, the design of transmission teaching aids need to cater to learning interests.
3.1.2. Thinking barrier. Children 6-12 years old are in the specific calculation stage. Although the formation of children's thinking at this stage has been generated through specific content calculations, some words are still incomprehensible to children for a short time, such as: speed, millimeters and meters. Therefore, in the design of transmission teaching aids, how to form abstract knowledge is also a factor that needs to be considered in teaching aid design.

3.1.3. Attention barrier. Attention is divided into intentional attention and unintentional attention[7]. Children in this period will often be distracted, by trivial sounds, colorful colors and other factors that make it difficult to concentrate, teaching aids design is a system that guides children to receive knowledge, so it needs to purposefully attract children's attention.

3.1.4. Memory barrier. Children in this period mainly guide they implicit learning. If the memory task is reminiscent of a few years, and then recognize the pattern, it is still easy to forget, for example: a word is copied ten times, but it can not be stored in the long term memory in the process of experiencing things. The formation of emotions and moods will extend the memory time and 
form implicit memory. Therefore, in the design of transmission teaching aids, active cognitive processing should be formed actively instead of passively.

\subsection{The relationship between children's cognitive characteristics and the purpose of teaching aid design}

\subsubsection{Attracting Attention-Stimulating Neural Development and Guiding Implicit Learning}

All knowledge transmission must be based on children's interests. How to attract children's interests is the beginning of knowledge that can be actively explored. Children must have different emotional reactions in the process of experience. Psychologists define emotions as specific stimulus responses[8]. Studies have shown that the memory of pleasant stimuli is more accurate than the memory of other stimuli. Therefore, the purpose of transmission teaching aids is to stimulate children's emotions in interesting ways and establish an autonomous association of knowledge.

\subsubsection{Establishing experiential situations- establishing first-hand experience and forming autonomous thinking}

By letting the children directly operate the transmission teaching aids, they can get feelings from them, generate doubts, and then put the predecessor's theory back into things to understand, realistically test, and creatively propose ideas (solve the problem). Creating different moods in the context experience can form a more general and long-term experience. Unlike the education model of static speaking in "learning by doing ", through a lot of self-practice processes, the memory is no longer an explicit memory, and children can easily extract materials from it to form their own knowledge system.

\subsubsection{Follow the logic of life-unclog the psychological defense and build a knowledge channel}

Children's cognitive range depends on life experience, and the accumulation of sensory experience also expands the cognitive range of life experience. The cognitive range is related to the psychological defense of safety. Children usually establish effective learning in familiar things or the extended information of things. Therefore, the design of children's teaching aids must follow the logic of life, and life experience will assist sensory understanding, this kind of reduction and repetitive learning is most effective.

\section{Design and practice of transmission teaching aid}

\subsection{Combining life with fun}

The interestingness of teaching aids is also an incentive to attract children. Engineering construction reflects the industriality and accuracy of modern society, and the engineering components alone seem relatively rational. As shown in Figure 2. for children aged 6-12, it is difficult to form an understanding memory. The combination of teaching aids and things in life is convenient for children to establish the logic system of engineering transmission in life, and to form their own cognitive inquiry into engineering transmission. As shown in Figure 3. and Figure 4, the crank-rocker mechanism is combined with a bicycle and an airplane, and the crank-rocker structure is integrated from independent components. The transmission device at this time is no longer a rigid part, more it is the enlargement of life forms. It promotes children to produce a more intuitive image of a single transmission, and at the same time, strengthens their sensitivity to the details of life. In the future study and life, when children see bicycles and airplanes, they may be affected by curious or fun to delve into the transmission structure and establish an active learning process inadvertently in life.

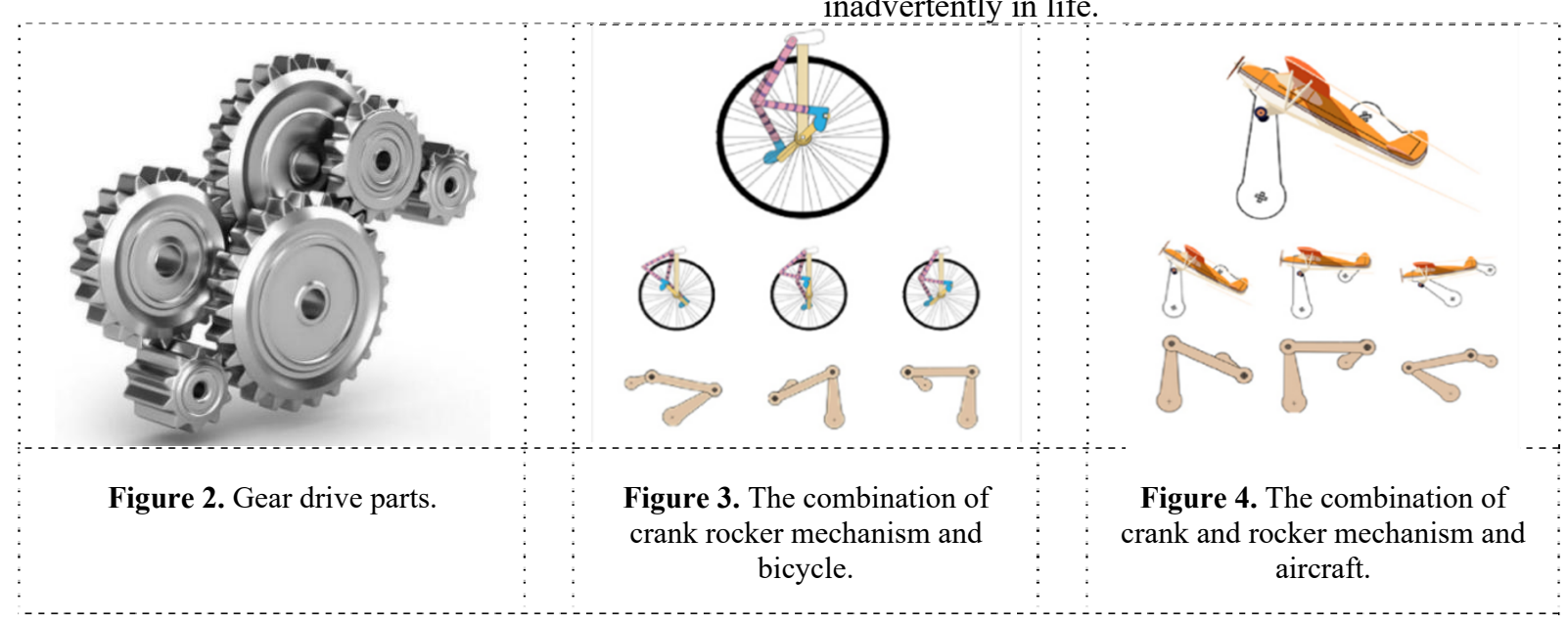




\subsection{Setting up the situation, dynamic presentation}

According to Montessori early childhood education theory, sensory education can guide children's behavior[9]. Through the concentration of characteristic visual images, it can constitute a story-like scene and create a world with children's spirit. As shown in Figure 5. The crank slider mechanism is integrated with penguin fishing, which brings the children closer to the mechanical engineering, and it is easy to form a pleasant emotional learning experience. The pleasant learning experience is more effective and accurate than the unpleasant learning experience. Figure 6 . The crank and rocker mechanism combined with the animation of cats and mice, on the one hand, it intuitively shows the operating rules of such mechanisms, and on the other hand, it gives this ordinary mechanical structure a story. While playing, children can establish first-hand experience and understand the operating rules of the entire teaching aid. In fact, the process of setting up the situation also further guides children's thinking divergence. They may have questions about how to turn the mouse to fall or how the mouse climb the smallalarm clock. Whether it is the divergent thinking about the mechanical structure or the imagination of the storyline, it is conducive to stimulating children to explore Figure 7. combines the reciprocating mechanism with the big shark's annexation of the small fish to harmonize the entire story dynamically. Compared with the traditional dictated knowledge system of traditional teaching, the establishment of the situation is relatively easier to attract children and stimulates emotional responses. Furthermore, combining the institution with the situation, the entire teaching aid is dynamic with the manipulation of the situation. Compared with static teaching aids, the dynamic knowledge system is more likely to excite children.

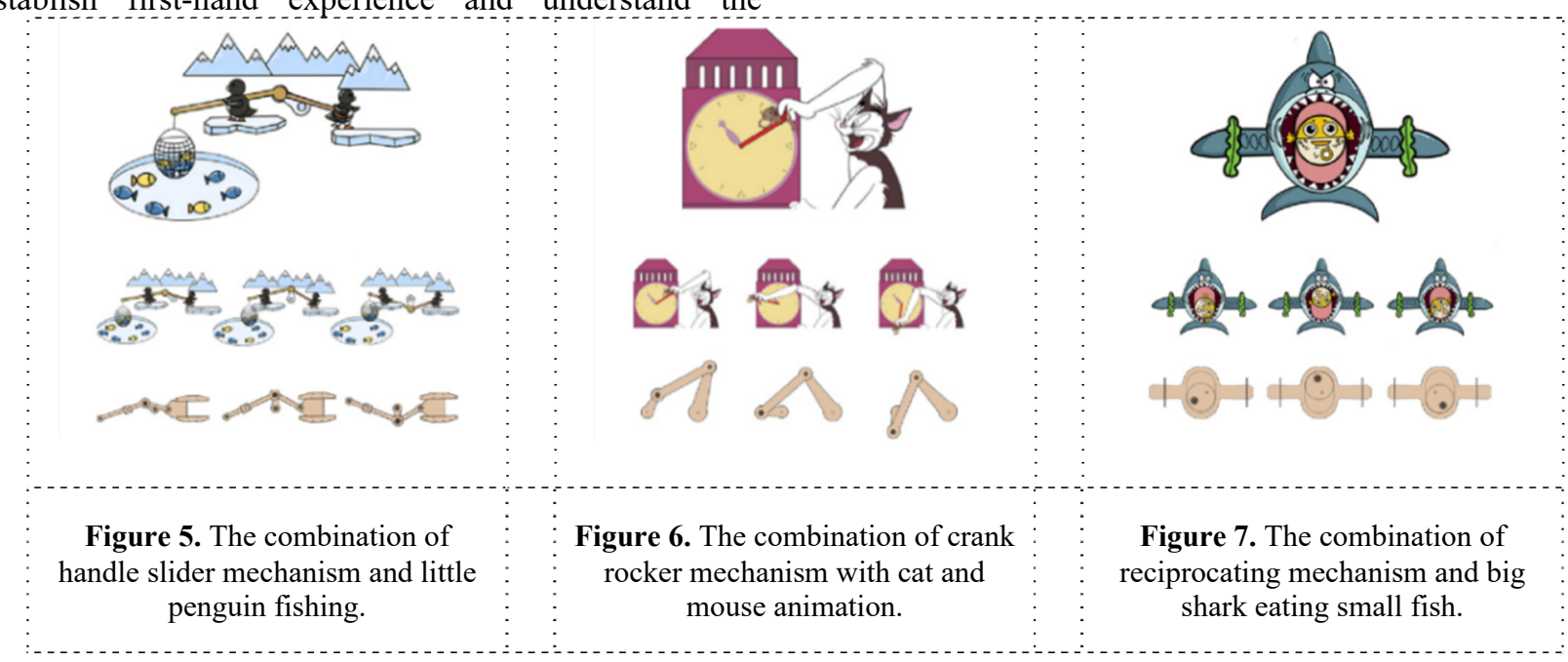

\subsection{Figurative cognition}

Of all the perceptual information input, visual information input accounts for more than $75 \%$. The sensory intake image provides a solid foundation for children to understand the material world. Therefore, this teaching aid design incorporates many cartoon elements to allow children to identify and experience the teaching aids. At that time, first get a far-end stimulus. Figure 8 . connects the reciprocating mechanism with ducklings playing in the water. For children, some knowledge is basically not in contact with previous experience, so how to concrete abstract knowledge and how to understand from the perspective of children's thinking is also a major factor to be considered in this design. For example, words such as speed and rotation ratio, if not doing by children themselves, it is really difficult to form a long-term memory. Figure 9. Combines the planetary gear mechanism with the cosmic system. when children are experiencing manipulation, they can more intuitively see the direction of the structure's operation which guides children to think about a series of problems such as the law of rotation and the direction of rotation, making the abstract knowledge system more specific and intuitive. Figure 10. combines the swing rocker mechanism with the image of the circus, giving the transmission mechanism a more intimate side. 


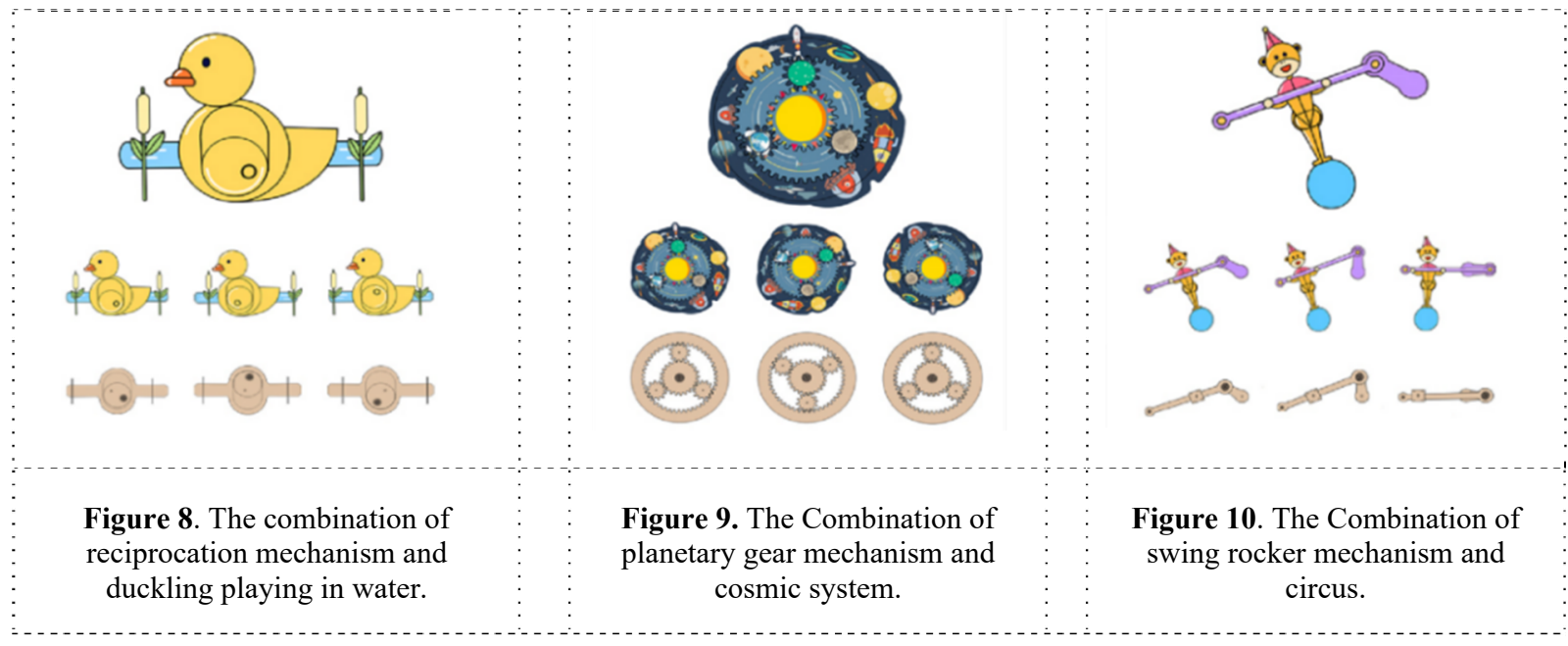

\subsection{Self-assembly, mechanics practice}

Children aged 6-12 need many activities, and they are full of interest and creativity in things that can be moved, so the driving teaching aids can also help children develop fine sense of touch and promote hand-eye coordinated development. Montessori research has shown that teaching aids fun alone is not enough. It must be beneficial for children to engage in certain activities in order to allow children to develop better. Preschool children can repeatedly operate simple things, install and remove, and remove and install. This process also promotes the development of five senses and brain . Figure 11. sets up a situation where two fencers play against each other, and the mechanical structure is independent, which inspires children's conscious assembly and enhances children's creativity. It is also an exercise in error control while selfassembly. Learning is a process which needs to repeat continuously, and during the installation process, the parts sometimes can not be connected. Therefore, when children are splicing, they need to continue to self-correct. While cultivating children's endurance, they also subconsciously improve their ability of judgement.

In this process, children gain more learning experience through self-practice. Through continuous errors, they form their own engineering transmission cognitive system for the engineering transmission parts to the overall operation. After discovering the wrong self and correcting the mistake to promote self-reflection and potentially guide self-implicit learning.

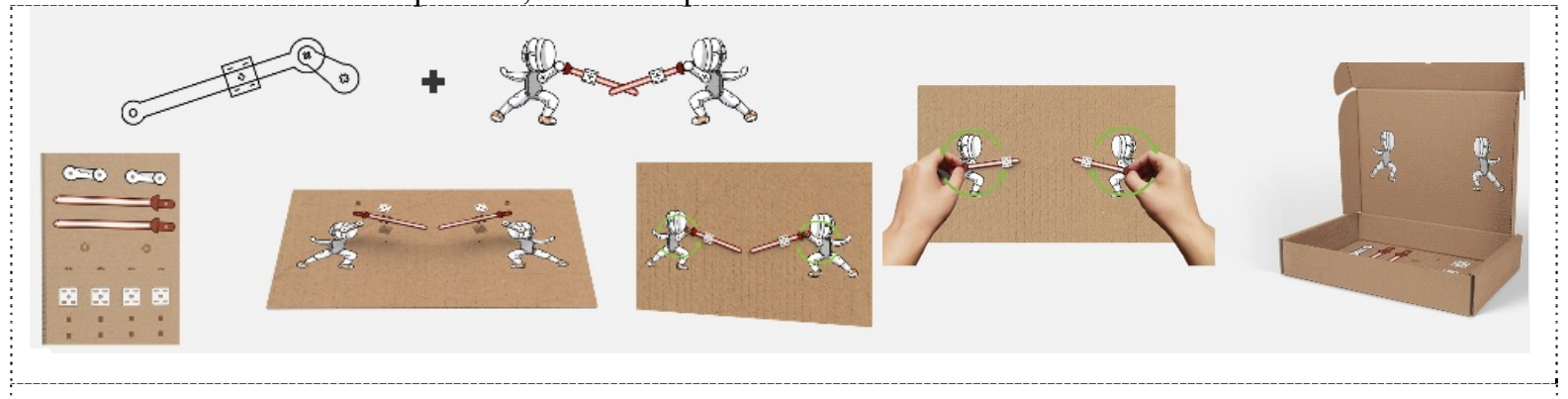

Figure 11. Setting up situation and independence of mechanical structure.

\section{Conclusion}

In 1978, china's one-child policy officially was written in the constitution of China, which advocated a couple to have one child. This policy was determined after the central government held five population seminars in 1980[10], so most people born after 1980 were only children. Today the post-80s are considered to be parents and the age range of their children distributed around 6-12 years old, and its offspring are mostly only children. With the promulgation of the national second-born child policy, some families have two children. Two generations of the three-generation coexisting family structure are the only children. Compared with traditional multi-child families, their household consumption will be greatly reduced, and the accumulation of family economic wealth will be easier. Against the background of the development of a diversified education model, the accumulation of economic wealth will further strengthen the family's ability to resist risks. The children's refined training requirements gradually show their dissatisfaction with the disadvantages of test education, and at the same time, they are urgently looking for alternative models and innovative products. The educational philosophy of reducing active learning methods and children's cognitive laws are a matching relationship, which provides a theoretical basis for teaching aid design. The design of teaching aids is not only for the purpose of imparting knowledge to children. More importantly, it aims to make the children learn by 
themselves and be more creative. And compared with the traditional teaching method, the activity teaching method advocates "learning by doing, learning by playing". The design of transmission teaching aids continues to attract children's attention, stimulate information stimulus, guide implicit learning, and set up experiential situations to form the principle of autonomous thinking. It combines teaching aid knowledge with life logic and abstract knowledge to concretely visualize. Setting up story situations can stimulate children's interest, and set assembly practice links and make fine mistakes can control and guide children's operation and reflection. We can take the basic knowledge as the carrier and master the learning methods in the activity, fully mobilize the enthusiasm and initiative of children's learning, and stimulate the cultivation of students' innovative spirit and practical ability. This research belongs to 2018 Practical content of the "Thirteenth Five-Year Plan" of education science in Liaoning Province (JG18DB308)[11].

\section{References:}

1. Shan, M.X. (2015) Investigation and analysis of effective teaching in American colleges and universities: Taking the university of Florida as an example. Higher Education Exploration, 09:56-60.

2. Du, J., Yu, F. (2019) Innovation of interactive design of children's toys in structural games. Design, 05: 60-62.

3. Lu, Y.G., Cheng, W.M. (2018) Orderly connection between junior middle school physics and primary school science based on thinking method. Physics Teacher, 08: 47-49.

4. Ge, X.Y., Bao, H.M.(2019) Modular glider children's teaching aid design.Design, 15: 128-131.

5. Liu, H.X. reserach China. (2017) Design of Children's Activity Space in "learning by Playing ". https://www.cnki.net.

6. Ding, X. (2017) Design of the South China Sea tourism special service system based on the five senses experience. Packaging Engineering, 10: 2430 .

7. Liu, Z.J., Li, X. (2019) Children's digital reading product design based on Augmented Reality Technology, Packaging Engineering, 08: 197-203.

8. Miao, Y.M. reserach China. (2009) Experimental study on the effects of visual-audio stimuli on emotional autonomic physiologically activities. https://www.cnki.net.

9. Hong, M., Gao, Z.P. (2013) An International Paradigm of Preschool Teacher Education Curriculum-Analysis of Teacher Training Course of "International Montessori Association" (AMI) .In: Chinese Education Association, Shenzhen. pp. 165-178.

10. Zhan, Z.L., Xie, K.Z. (2011) Interpretation of Article 18 of the "Population and Family Planning Law". Population and Development, 03: 65-72.
11. Zhang, Y., Shao, Y.Y., Yu, H.J. (2018) Probe into the Long-term Mechanism of "Studio Model" Teaching Internal Quality Guarantee. MATEC Web of Conferences 176, 02010. 